\title{
Formulation and Evaluation of Floating Matrix Tablets of Ciprofloxacin Using Sida acuta Gum
}

\author{
Okafo Sinodukoo Eziuzo*, Ikechukwu Ifeoma Love and Alalor Christian \\ Department of Pharmaceutics and Industrial Pharmacy, Faculty of Pharmacy, Delta State University, Abraka, Delta State, Nigeria
}

*Corresponding author: Okafo Sinodukoo Eziuzo, Department of Pharmaceutics and Industrial Pharmacy, Faculty of Pharmacy, Delta State University, Abraka, Delta State, Nigeria, Tel: +2348063386118E-mail: sinokaf@yahoo.com

Received March 14, 2019; Accepted March 21, 2019; Published March 27, 2019

\begin{abstract}
Background: Natural polymers have been found to be affordable, easily available, biocompatible and biodegradable. This study was conducted to formulate and evaluate floating matrix tablets of ciprofloxacin using Sida acuta gum (SAG) as hydrophilic polymer.

Methods: Sida acuta gum was isolated from the dried powdered leaves of Sida acuta plant by isopropyl alcohol precipitation of the filtrate obtained from its maceration in distilled water. The gum obtained was used to formulate ciprofloxacin floating tablets using direct compression technique. The tablets were evaluated for hardness, friability, uniformity of content, floating lag time, total buoyancy time, in vitro drug release, kinetics and mechanism of release.

Results: The formulated tablets gave hardness range of $3.80 \pm 0.56$ to $5.01 \pm 0.61$; uniformity of content value range from 99 to $106 \%$, friability values obtained range from 0.44 to $2.41 \%$, and formulated tablets had buoyancy time greater than 12 hours, floating lag time values ranged from $<1 \mathrm{~min}$ to $90 \mathrm{~min}$. Tablets formulated with $20 \%$ hydroxypropylmethylcellulose, HPMC (CF4) gave the highest swelling value of almost $5000 \%$. The drug release profile for the floating tablet formulations after $7 \mathrm{~h}$ was $110 \%, 72 \%, 106 \%, 46 \%$ and $87 \%$ for CF1 (20\% SAG), CF2 (30\% SAG), CF3 (15/15\% SAG and HPMC), CF4 (20\% HPMC), CF5 (20\% Sodium carboxymethylcellulose) respectively.
\end{abstract}

Conclusion: This study showed that ciprofloxacin floating matrix tablets that have sustained release property could be formulated using Sida acuta gum as the hydrophilic polymer.

Keywords: Ciprofloxacin; Floating tablets; Sida acuta gum; Matrix tablets; Sustained release property

\section{Introduction}

Most drugs are usually administered through the oral route because it is easier to do so compare to other routes and this leads to better patient compliance. Formulation of oral drugs is usually simple and flexible. Oral dosage forms have a draw back in that due to the variability in gastric emptying time, some may be ejected from the gastric region before the drug is released from the dosage form. This draw back can be resolved by designing drugs that are retained in the gastric region for a long period. This could result in increased bioavailability, decrease in drug waste and enhancement of the solubility of a drug that is less soluble at high $\mathrm{pH}$ concentration $[1,2]$.

Floating or low density system is one of the mechanisms used in the formulation of gastro-retentive dosage forms [3]. In floating systems; the drug is released slowly as it floats on the gastric contents, after which, the residual system is eliminated from the stomach and this leads to extended gastric retention time as well as better control of the variations in plasma drug concentration [4].

Floating systems could be either the effervescent or noneffervescent type. Effervescent systems are matrix type systems. They are produced by compressing a mixture of polymer that swells (e.g., sodium carboxymethylcellulose) and effervescent components like sodium bicarbonate, calcium carbonate, citric acid or tartaric acid. They give out carbon dioxide when they come in contact with gastric juice in the stomach. The carbon dioxide released is trapped in the swollen hydrocolloids and provides buoyancy to the dosage form.

Drugs that are good candidates for formulation into floating drug delivery systems include drugs which have site-specific absorption in the stomach or upper parts of the small intestine (chlordiazepoxide); drugs that exert local therapeutic action in the stomach (antacids), drugs that degrade in the lower part of gastrointestinal tract (metronidazole), drugs that are insoluble in intestinal fluids (diazepam), drugs that disturb the normal colonic bacteria (amoxicillin trihydrate) $[1,2]$.

Ciprofloxacin hydrochloride is an antibacterial agent which is absorbed mainly from the stomach and the proximal part of the small intestine [5]. It is a fluoroquinolone and is active against both gram negative and positive bacteria. Its oral bioavailability is $70 \%$ and a peak plasma concentration of $2.5 \mu \mathrm{g} / \mathrm{ml}$ is reached in 1 to $2 \mathrm{~h}$ after administration of $500 \mathrm{mg}$ dose. Ciprofloxacin has a relatively short elimination half life $(\mathrm{t} 1 / 2=4 \mathrm{~h})$, therefore, a slow-release formulation could reduce variations in the therapeutic effect and so improve its clinical efficacy [6]. The sustained release dosage form has a disadvantage of reduction in absorption as the tablet passes down the GIT, [7] but this is overcome using the floating tablet.

Previous researchers have shown that in the formulation of Floating tablets that formulation variables like polymer type, polymer ratio, polymer concentration, and sodium bicarbonate concentration have significant effect on release rate, cumulative release and floating lag time, but not on floating duration $[7,8]$.

Sida acuta gum is derived from the powdered dried leaves of Sida acuta by isopropyl alcohol precipitation of the filtrate from its maceration in distilled water [9]. Sida acuta gum was used in tablet formulations as binder, [10] as hydrophilic polymer matrix, [11] and as suspending agent in formulation of paracetamol suspensions [12].

This study was carried out to formulate and evaluate floating matrix tablets of ciprofloxac in using Sida acuta gum as the hydrophilic polymer.

\section{Materials and Methods}

\section{Materials}

Chemicals used were of analytical grade, they include; ciprofloxacin, 
microcrystalline cellulose (MCC), sodium bicarbonate, citric acids (Loba Chemie, Mumbia, India), hydroxypropyl methylcellulose (HPMC), sodium carboxymethyl cellulose (NaCMC), magnesium stearate, talc (BDH Chemicals Ltd Poole England), hydrochloric acid, ethanol, isopropyl alcohol and acetone (Guangxing Guanghua Chemical, China). Sida acuta gum was isolated from the leaves of Sida acuta collected from the botanical garden of Faculty of Pharmacy, Delta State University, Abraka.

\section{Isolation and purification of Sida acuta gum}

Fresh Sida acuta leaves were sun dried and milled. The method of Okafo and Chukwu [8] was used in the isolation of the gum. The purified gum was dried in an oven (Veego instruments, Mumbai India) at $40^{\circ} \mathrm{C}$ for $8 \mathrm{~h}$. The dried gum was pulverized and screened using a 300 $\mu \mathrm{m}$ stainless steel sieve. The gum was stored in a dry, air-tight container.

\section{Pre-compression evaluation}

Ciprofloxacin powder and the excipients were mixed properly and evaluated for their flow properties using their bulk and tapped densities as parameters.

Bulk and tapped densities: A 10 g quantity of the powder blend from each of the formulations was weighed and transferred into a measuring cylinder. The volume occupied was recorded as the bulk volume. Thereafter, the measuring cylinder was tapped 100 times on a padded surface and the new volume occupied was recorded as the tapped volume. This process was repeated twice for all the formulations. The tapped and bulk densities were calculated using equations 1 and 2 respectively.

$$
\begin{aligned}
& \text { Bulk density }=\frac{\text { Weight of powder blend }(\mathrm{g})}{\text { Bulk volume }(\mathrm{ml})} \\
& \text { Tapped density }=\frac{\text { weight of powder blend }(\mathrm{g})}{\text { Tapped volume }(\mathrm{ml})}
\end{aligned}
$$

Carr's compressibility index:

$$
\text { Carr's index }=\frac{\text { tapped density }- \text { bulk density }}{\text { tapped density }} \times 100
$$

\section{Hausner's ratio:}

$$
\text { Hausner's ratio }=\frac{\text { tapped density }}{\text { bulk density }}
$$

\section{Preparation of ciprofloxacin floating matrix tablets}

Direct compression method was used in the preparation of the ciprofloxacin floating matrix tablets using the formula (Table 1). Ciprofloxacin powder was mixed with different concentrations of polymer (Sida acuta gum, HPMC, or NaCMC), MCC, sodium bicarbonate and citric acid. The powder - mix was properly blended, thereafter magnesium stearate and talc were added with slight blending. The powder blend was compressed into tablets using a single punch tableting machine fitted with $13 \mathrm{~mm}$ punch (Manesty, Liverpool, UK).

\section{Post-compression evaluation}

Uniformity of weight: Twenty tablets were randomly selected and weighed individually. The mean weight of the tablets and the deviation from the mean for each tablet were calculated and recorded.

Thickness, diameter and hardness tests: Six tablets from each formulation were selected at random and inserted individually into the tablet chamber of a digital tablet hardness test apparatus (DIGITAB model, Veego instruments, Mumbai, India). The hardness, thickness and diameter values displayed were recorded.
Content uniformity test: Five tablets from each formulation were weighed together and crushed to powder. A $0.12 \mathrm{~g}$ quantity of the powder (equivalent of $0.05 \mathrm{~g}$ of ciprofloxacin) was weighed and transferred into a $100 \mathrm{ml}$ volumetric flask. A $100 \mathrm{ml}$ quantity of $0.1 \mathrm{~N} \mathrm{HCl}$ was introduced into the flask, shaken for $15 \mathrm{~min}$ and filtered using a filter paper. Three aliquots were taken from the stock solution and each diluted suitably $(500,250,125,62.5,31.25,15.63 \mu \mathrm{m})$. They were analyzed for their ciprofloxacin contents using a UV/visible spectrophotometer (UV1800, Shimadzu Japan) and the drug content were calculated from the equation obtained from the standard calibration curve of ciprofloxacin prepared using $0.1 \mathrm{~N} \mathrm{HCl}$. This procedure was repeated for all the formulations.

Friability test: Ten tablets from each formulation were weighed together and placed in the drum of friabilator (Veego digital friabilator, Veego instruments, Mumbai, India). The drum was rotated at $25 \mathrm{rpm}$ for $4 \mathrm{~min}$. The tablets were carefully weighed after dusting. The friability (\%) for all the formulations were calculated respectively using the equation 5 .

$$
\% \text { friability }=\frac{\text { initial weight }- \text { final weight }}{\text { initial weight }} * 100
$$

\section{Swelling index study}

The method used by previous researchers $[11,13]$ was used. The swelling properties of the formulated tablets were evaluated by taking the initial weight of the tablets. A $30 \mathrm{ml}$ of distilled water was measured and added to the Petri dish containing each tablet. At intervals of 1, 2, 3, 4,5 and $6 \mathrm{~h}$ respectively, the water in the Petri dish was drained using a tissue paper. The final weights of the tablets were recorded. The swelling index was calculated using equation 6 .

$$
\text { Swelling index }=\frac{W f-W i}{W i} * 100
$$

Where $\mathrm{Wf}=$ final weight of tablet, and $\mathrm{Wi}=$ initial weight of tablet.

\section{In vitro buoyancy or floating study}

A tablet from each of the ciprofloxacin tablet formulations was gently dropped into a $100 \mathrm{ml}$ beaker containing $0.1 \mathrm{~N} \mathrm{HCl}$. The time taken for the tablet to rise to the top was recorded as the floating lag time. The duration of time the tablet remained afloat was recorded as the total floating or buoyancy time.

\section{In vitro drug release study}

The in vitro dissolution test was carried using USP apparatus 2. One tablet was placed in the basket of the dissolution chamber containing $900 \mathrm{ml}$ of $0.1 \mathrm{~N} \mathrm{HCl}$ maintained at $37 \pm 2^{\circ} \mathrm{C}$ as the dissolution medium. The basket was rotated at $100 \mathrm{rpm}$. At predetermined time intervals, $0.5,1,2,3,4,5,6$ and 7 hours, $5 \mathrm{ml}$ samples were withdrawn and replaced with fresh preheated medium respectively. Aliquots obtained were filtered and diluted. The sample was analyzed using the UV/visible spectrophotometer (UV - 1800, Shimadzu Japan) at a wavelength of $272 \mathrm{~nm}$. The percentage drug released was calculated using the equation obtained from the calibration curve.

\section{In vitro drug mechanism and kinetics of release}

The kinetics of release of ciprofloxacin from formulations CF1 to CF5 in $0.1 \mathrm{~N} \mathrm{HCl}$ were determined by the application of the zero order, [14] first order, [14] Higuchi [14,15] and Hixson - Crowell's cuberoot law [16] to the cumulative drug release using equations 7 to 10 . The mechanism of drug release was obtained by fitting the first $60 \%$ drug release data into the Korsmeyer - Peppas model $[17,18]$ as in equations 11 and 12 . 


\section{Zero order model}

$$
C=K_{0} t
$$

$\mathrm{C}=\%$ Release, $\mathrm{K}_{0}=$ Zero Order rate constant expressed in units of concentration/time $(\mathrm{t})$.

\section{First order model}

$$
\log C_{r}=\log C_{0}-K_{1} t / 2.303
$$

$\mathrm{Cr}=\%$ Remaining, $\mathrm{C} 0=$ Initial concentration of drug, $\mathrm{K} 1=$ First Order constant, $\mathrm{t}=$ Time.

Higuchi's square root law model

$$
Q=K_{H} t^{1 / 2}
$$

$\mathrm{Q}=\%$ Released, $\mathrm{KH}=$ Constant reflecting design variables of the system, $\mathrm{t}=$ Time.

\section{Hixson-Crowell's cuberoot law model}

$$
[(100-f) / 100]^{1 / 3}=1-K_{H C} t
$$

$\mathrm{f}=\%$ Released, $\mathrm{KHC}=$ Rate constant, $\mathrm{t}=$ Time.

\section{Korsmeyer-Peppas model}

$$
\begin{aligned}
& M t / M \infty=K t n \\
& \log M t / M=\log K+n \log t
\end{aligned}
$$

Where, $\mathrm{Mt} / \mathrm{M} \infty$ is the fraction of drug released at time $\mathrm{t}, \mathrm{k}$ is the rate constant and $\mathrm{n}$ is the release exponent. The $\mathrm{n}$ value is used to characterize different release mechanisms for cylindrical shaped matrices [17-19].

\section{Results and Discussion}

\section{Bulk and tapped densities of ciprofloxacin-excipients blend}

The results in Table 2 showed that Carr's index values of the formulations ranged from $29.00 \pm 0.46$ to $43.00 \pm 0.78$, while their Hausner's ratio was from $1.40 \pm 0.02$ to $1.74 \pm 0.01$. According to the specifications in British Pharmacopoeia (2012), the values for formulations CF1 and CF5 indicated poor flow, while CF2 and CF4 had very poor flow. However, their flow could be improved upon by the addition of glidants such as aerosol or talc, or augmentation of their feeding through the hopper. The values for formulation CF3 showed a very, very poor flow. Its flow through the hopper need to be augmented or the formulation reformulated through non - aqueous granulation in order to improve flow.

\section{Post compression evaluation}

Hardness and friability: Hardness values for the formulations ranged from 3.80 to $5.01 \mathrm{~kg} / \mathrm{f}$ as shown in Table 2 . Friability of the tablets ranged from $0.44 \pm 0.02$ to $0.62 \pm 0.16 \%$ for CF1, CF2, and CF4 which indicated compliance with the acceptable limit $(<1 \%)$. Hardness and friability test were carried out to evaluate the mechanical and breaking strength of the prepared tablets. The result obtained showed that the prepared ciprofloxacin floating tablets could withstand handling, shipping and other production procedures. Formulations CF3 and CF5 had values exceeding 2.0 which were above the limit for friability, but with proper packaging in blister packs, the tablets structural integrity could be kept intact.

Weight and content uniformity: The per cent deviation of the individual tablet's weight from the mean weight ranged from 0.1 to $0.2 \%$ and this indicates compliance with the USP limit of $\pm 5.0 \%$ for tablets weighing $250 \mathrm{mg}$ and above. As shown on Table 3, the drug content (\%) of ciprofloxacin tablets was between $99-106 \%$ which was within the

\begin{tabular}{|l|c|c|c|c|c|}
\hline Ingredients & CF1 & CF2 & CF3 & CF4 & CF5 \\
\hline Ciprofloxacin (mg) & 250 & 250 & 250 & 250 & 250 \\
\hline Sida acuta gum (mg) & 120 & 180 & 90 & - & - \\
\hline HPMC (mg) & - & - & 90 & 120 & - \\
\hline NaCMC (mg) & - & - & & - & 120 \\
\hline Sodium bicarbonate (mg) & 100 & 100 & 100 & 100 & 100 \\
\hline Citric acid (mg) & 30 & 30 & 30 & 30 & 30 \\
\hline Microcrystalline cellulose (mg) & 82 & 22 & 22 & 82 & 82 \\
\hline Magnesium stearate (mg) & 6 & 6 & 6 & 6 & 6 \\
\hline Talc (mg) & 12 & 12 & 12 & 12 & 12 \\
\hline Total (mg) & 600 & 600 & 600 & 600 & 600 \\
\hline
\end{tabular}

Table 1: Composition of floating matrix tablets of ciprofloxacin.

Key: C1 $=20 \%$ Sida acuta gum, C2 $=30 \%$ Sida acuta gum, C3=15\% Sida acuta and $15 \%$ HPMC, C4=20\% HPMC, C5=20\% NaCMC.

\begin{tabular}{|c|c|c|c|c|}
\hline Formulations & $\begin{array}{c}\text { Bulk density } \mathbf{\pm} \\
\text { SD }(\mathbf{g} / \mathbf{m l})\end{array}$ & $\begin{array}{c}\text { Tapped density } \\
\mathbf{\pm} \text { SD }(\mathbf{g} / \mathbf{m l})\end{array}$ & $\begin{array}{c}\text { Carr's index } \mathbf{~} \\
\text { SD }(\%)\end{array}$ & $\begin{array}{c}\text { Hausner's } \\
\text { ratio } \pm \text { SD }\end{array}$ \\
\hline CF1 & $0.33 \pm 0.01$ & $0.48 \pm 0.01$ & $29.00 \pm 0.56$ & $1.42 \pm 0.01$ \\
\hline CF2 & $0.33 \pm 0.01$ & $0.50 \pm 0.00$ & $33.00 \pm 0.10$ & $1.50 \pm 0.02$ \\
\hline CF3 & $0.25 \pm 0.02$ & $0.43 \pm 0.01$ & $43.00 \pm 0.78$ & $1.74 \pm 0.01$ \\
\hline CF4 & $0.31 \pm 0.00$ & $0.45 \pm 0.02$ & $31.00 \pm 1.15$ & $1.45 \pm 0.03$ \\
\hline CF5 & $0.36 \pm 0.00$ & $0.50 \pm 0.01$ & $29.00 \pm 0.46$ & $1.40 \pm 0.02$ \\
\hline \multicolumn{4}{|c}{ Table 2: Micromeritics of ciprofloxacin - excipients blend. } \\
\hline
\end{tabular}

USP limit of (90-110\%). Proper mixing of powders for granulation or compression leads to less variation in tablet weights and also in drug content.

Buoyancy test: The floating lag time for CF1, CF3 and CF4 as shown in Table 4 was between 1 and $3 \mathrm{~min}$. This indicated excellent floating lag time. CF5 had a floating lag time of $14 \mathrm{~min}$ while it took $\mathrm{CF} 2,1.5 \mathrm{~h}$ to float. This shows that formulation CF2 may be expelled from the stomach before it starts floating and this may lead to failure of the dosage form. The buoyancy time for all the formulations was above $12 \mathrm{~h}$.

Swelling study: Figure 1 showed that ciprofloxacin formulation that contained HPMC as the hydrophilic matrix (CF4) swells very fast, almost $5000 \%$ of its initial weight within $1 \mathrm{~h}$. Ciprofloxacin tablets from the other formulations swell just above $2000 \%$ of their initial weight. After $4 \mathrm{~h}$, the formulation that contained NaCMC (CF5) swells up to $4000 \%$ of its initial weight. Formulation CF3 that contains SAG/NaCMC $(15 \% / 15 \%)$ had a higher swelling capacity than the formulations that contained only SAG (CF1 and CF2).

The tablet formulations were also evaluated based on their swelling abilities. Swelling is a phenomenon that shows a hydrated polymer's hydrophilicity and ionization of its functional group; this therefore, controls the characteristics of the formed network structure. The swelling index describes the extent of the absorption of water within the hydrated polymer at equilibrium [20].

In vitro drug release: The results in Figure 2 showed that formulation CF1 would not be good as a sustained release formulation as it released more than $70 \%$ of its drug content within one hour. CF2 and CF5 released about $70 \%$ of their drug content in $6 \mathrm{~h}$ which showed moderate sustained release property. CF 3 and CF 4 released less than $70 \%$ of their drug content in $6 \mathrm{~h}$ though unlike CF4, CF3 released about $100 \%$ of its drug content in $7 \mathrm{~h}$. This showed that SAG at a concentration of $30 \%$ or in combination with HPMC $(15 \% / 15 \%)$ could be used to formulate sustained release ciprofloxacin floating matrix tablets that are comparable to those formed using standard hydrophilic polymers, HPMC and NaCMC. 


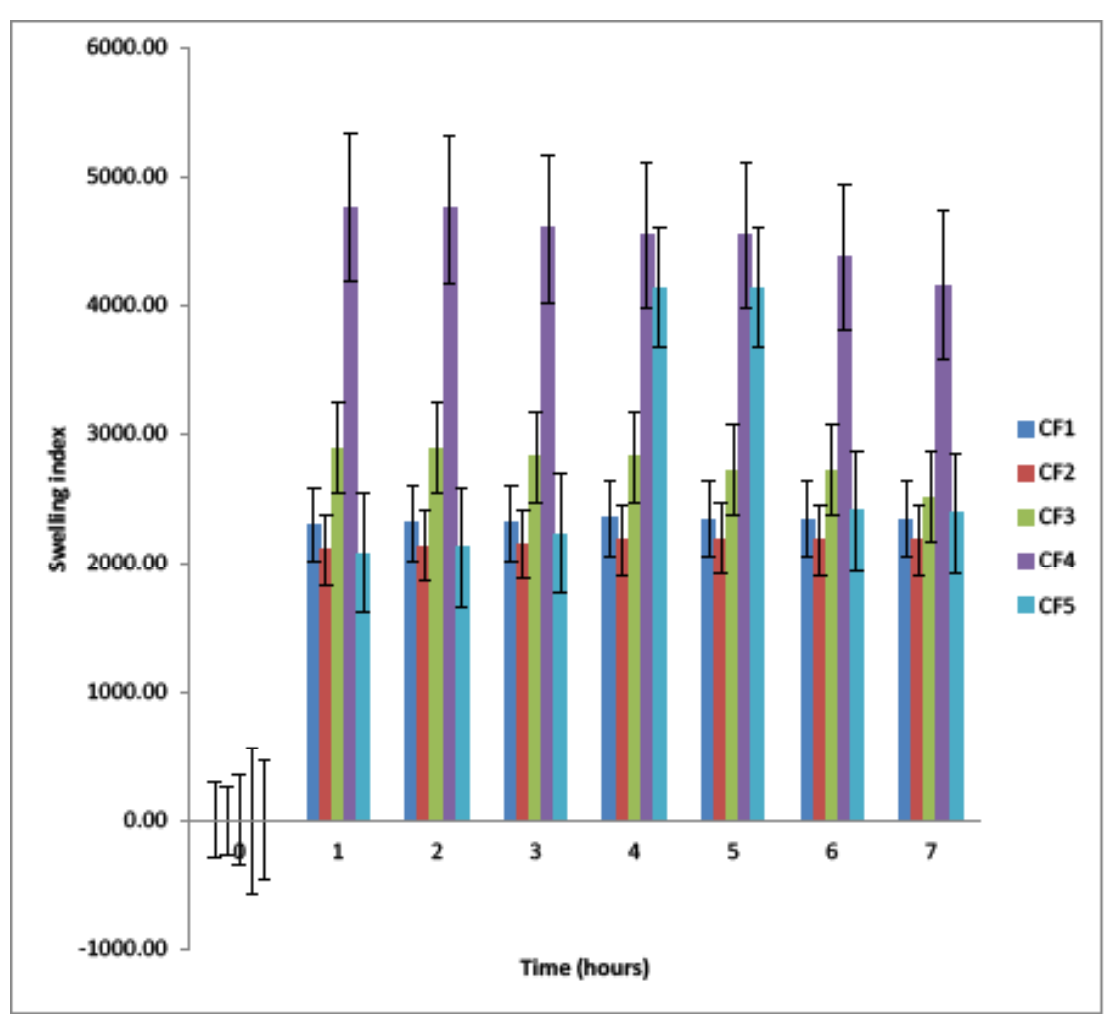

Figure 1: Swelling index of ciprofloxacin tablets from the different formulations after $7 \mathrm{~h}$.

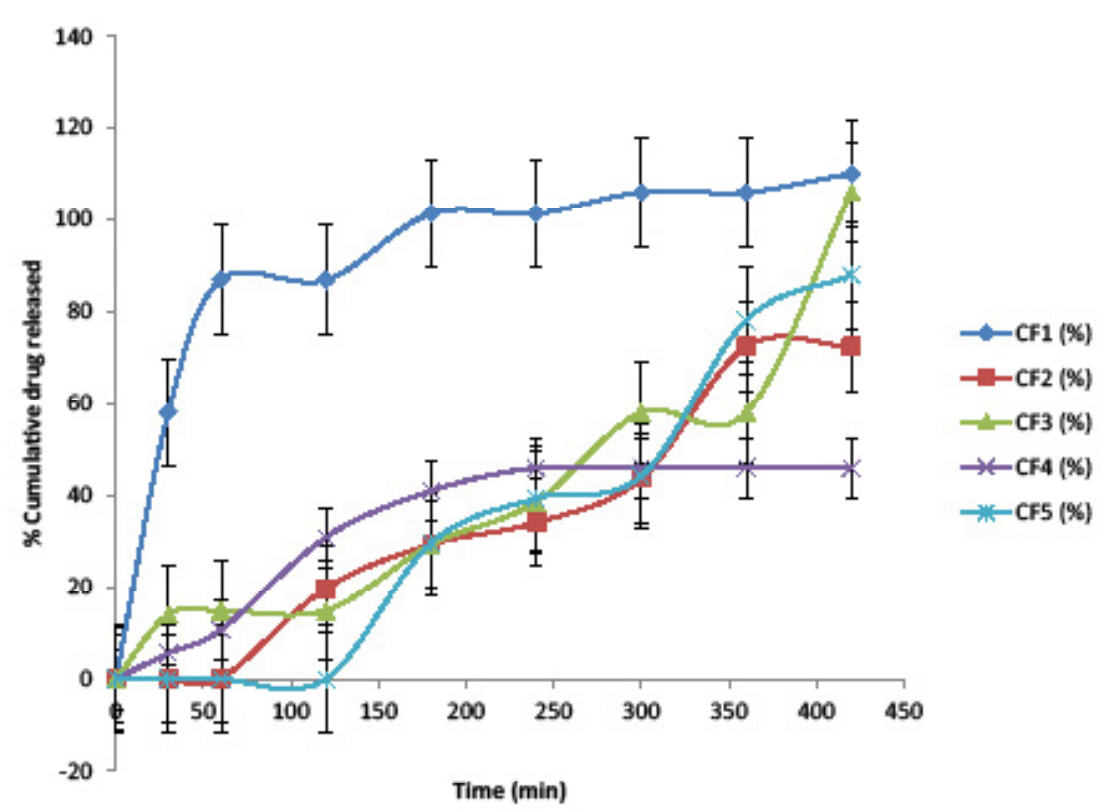

Figure 2: In vitro drug release profile of ciprofloxacin from the floating matrix tablets. Key: CF1=20\% SAG, CF2 $=30 \%$ SAG, CF3 $=15 \%$ SAG $\%$ HPMC, CF $4=20 \%$ HPMC, and CF5 $=20 \%$ NaCMC.

In vitro mechanism and kinetics of release: Formulation $\mathrm{CF} 1$ was not able to sustain the release of the ciprofloxacin content; therefore it could not fit well into any of the kinetic release models. The zero order model was the predominant kinetics of release for formulations CF2 and CF5, though first order and Hixson - Crowell model still contributed to the release of formulation CF2. Hixson - Crowell model was the prevalent kinetics of release for formulation CF3. Higuchi model was the predominant release model for formulation CF4 (Table 5).

The mechanism of release using the $\mathrm{n}$ - value from Korsmeyer Peppas model was by super case II transport for formulations CF1 and 


\begin{tabular}{|c|c|c|c|c|}
\hline Formulations & $\begin{array}{c}\text { Hardness } \\
\text { (kg/f) } \pm \text { SD }\end{array}$ & $\begin{array}{c}\text { Friability } \\
(\%) \pm \text { SD }\end{array}$ & $\begin{array}{c}\text { Weight } \\
\text { uniformity (\%) }\end{array}$ & $\begin{array}{c}\text { Content uniformity } \\
(\%) \pm \text { SD }\end{array}$ \\
\hline CF1 & $4.43 \pm 1.51$ & $0.50 \pm 0.10$ & 0.02 & $103.00 \pm 2.00$ \\
\hline CF2 & $5.01 \pm 0.61$ & $0.44 \pm 0.02$ & 0.01 & $106.00 \pm 4.20$ \\
\hline CF3 & $3.80 \pm 0.56$ & $2.40 \pm 0.12$ & 0.00 & $102.00 \pm 1.00$ \\
\hline CF4 & $4.21 \pm 0.39$ & $0.62 \pm 0.16$ & 0.01 & $100.00 \pm 0.00$ \\
\hline CF5 & $4.96 \pm 0.57$ & $2.05 \pm 0.05$ & 0.00 & $99.00 \pm 0.00$ \\
\hline
\end{tabular}

Table 3: Post compression properties of formulated tablets.

\begin{tabular}{|c|c|c|}
\hline Formulations & Floating lag time (min) & Buoyancy time (h) \\
\hline CF1 & $<1$ & $>12$ \\
\hline CF2 & 90 & $>12$ \\
\hline CF3 & 3 & $>12$ \\
\hline CF4 & 3 & $>12$ \\
\hline CF5 & 14 & $>12$ \\
\hline
\end{tabular}

Table 4: Buoyancy properties of ciprofloxacin tablets.

\begin{tabular}{|c|c|c|c|c|c|c|}
\hline \multicolumn{2}{|c|}{ Models } & CF1 & CF2 & CF3 & CF4 & CF5 \\
\hline \multirow{2}{*}{ Zero order } & $\mathrm{R}^{2}$ & 4.08 & 0.942 & 0.898 & 0.602 & 0.875 \\
\cline { 2 - 7 } & $\mathrm{K}$ & 0.349 & 0.167 & 0.206 & 0.140 & 0.184 \\
\hline \multirow{2}{*}{ First order } & $\mathrm{R}^{2}$ & 0.737 & 0.912 & 0.572 & 0.799 & 0.844 \\
\cline { 2 - 7 } & $\mathrm{K}$ & 0.004 & 0.001 & 0.003 & 0.000 & 0.002 \\
\hline \multirow{2}{*}{ Higuchi } & $\mathrm{R}^{2}$ & 0.736 & 0.762 & 0.734 & 0.908 & 0.658 \\
\cline { 2 - 7 } & $\mathrm{K}$ & 6.405 & 2.757 & 3.406 & 2.470 & 2.957 \\
\hline \multirow{2}{*}{ Hixson-Crowell } & $\mathrm{R}^{2}$ & 0.733 & 0.911 & 0.930 & 0.781 & 0.812 \\
\cline { 2 - 7 } & $\mathrm{K}$ & 0.004 & 0.000 & 0.000 & 0.000 & 0.000 \\
\hline $\begin{array}{c}\text { Korsmeyer- } \\
\text { Peppas }\end{array}$ & $\mathrm{R}^{2}$ & 1.000 & 0.995 & 0.964 & 0.984 & 0.973 \\
\cline { 2 - 7 } & $\mathrm{n}$ & 1.089 & 0.223 & 0.218 & 1.236 & 0.793 \\
\hline
\end{tabular}

Table 5: In vitro kinetics and mechanism of release of ciprofloxacin from the floating matrix tablets.

CF4, while anomalous (non - Fickian) diffusion was the mechanism of release of ciprofloxacin from formulation CF5 tablets. The mechanism of release of formulations $\mathrm{CF} 2$ and $\mathrm{CF} 3$ were not well defined though was close to Fickian diffusion.

According to Korsmeyer- Peppas model, when the value of $n=0.45$, then there is Fickian diffusion; if $0.45<\mathrm{n}<0.89$, it is anomalous (nonFickian) diffusion, $\mathrm{n}=0.89$, shows Case-II transport, while when $\mathrm{n}>0.89$, it results in Super case-II transport [17-19].

\section{Conclusion}

Floating matrix tablets of ciprofloxacin could be formulated using Sida acuta gum as the hydrophilic polymer matrix. Using SAG at $30 \%$ $\mathrm{w} / \mathrm{w}$ concentration, matrix tablets having sustained release property comparable to those formulated with HPMC or NaCMC could be produced.

\section{Acknowledgments}

The authors acknowledge the technical contributions of Mr. Ben Iwetan, Technologist in the Department of Pharmaceutics and Industrial Pharmacy, Faculty of Pharmacy, Delta State University, Abraka, Nigeria.

\section{References}

1. Manoj G, Rajesh P, Kapil KP, Mehta SC (2011) Floating drug delivery system. J Current Pharma Res 05: 7-18.

2. Nikita D (2011) Floating drug delivery system. J Current Pharma Res 7: 6-20.

3. Gupta NV, Shivakumar HG (2010) Preparation and characterization of superporous hydrogels as gastroretentive drug delivery system for rosiglitazone maleate. Daru 18: 200-210.

4. Mayavanshi AV, Gajjar SS (2008) Floating drug delivery systems to increase gastric retention of drugs: A review. Res J Pharma Tech 1: 345-348.

5. Varshosaz J, Tavakoli N, Roozbahani F (2006) Formulation and in vitro characterization of ciprofloxacin floating and bioadhesive extended-release tablets. Drug Delivery 13: 277-285.

6. Kumar VM, Rajat K, Saraogi GK, Singhai AK, Dharmendra S, et al. (2012) Formulation and evaluation of sustained release floating tablets of ciprofloxacin. Inter J Pharm 3: 120-122.

7. Kumar Arza RA, Rao Gonugunta CS, Veerareddy PR (2009) Formulation and evaluation of swellable and floating gastroretentive ciprofloxacin hydrochloride tablets. AAPS Pharm Sci Tech 10: 220-226.

8. Yilma Z, Belete A, Gebre-Mariam T (2015) Formulation and optimization of sustained release floating matrix tablets of salbutamol sulphate using xanthan gum and hydroxypropyl methylcellulose polymer blend. Inter J Pharma Sci Res 6: 1877-1892.

9. Okafo SE, Chukwu A (2017) Studies on Sida acuta hydrogel i: processing and physicochemical properties of the derived hydrogel obtained from South East Nigeria. Inter J Pharmacy Pharma Sci 9: 5-11.

10. Okafo SE, Chukwu A (2017) Evaluation of the binding property of Sida acuta gum in paracetamol tablet formulations. World J Pharma Res 6: 22-35.

11. Okafo SE, Chukwu A (2017) Formulation and evaluation of diclofenac matrix tablets containing a hydrophilic polymer, Sida acuta gum. World J Pharma Res 6: 36-47.

12. Okafo SE, Chukwu A (2017) Preliminary studies on the suspending properties of Sida acuta gum in paracetamol suspension. World J Pharma Res 6: 302-313.

13. Pcandey S, Shah RR, Gupta A, Arul B (2016) Design and evaluation of buccoadhesive controlled release formulations of prochlorperazine maleate. Int J Pharm Pharm Sci 8: 375-379.

14. Abdelkader $\mathrm{H}$, Abdalla OY, Salem $\mathrm{H}$ (2007) Formulation of controlled - release baclofen matrix tablets: influence of some hydrophilic polymers on the release rate and in vitro evaluation. AAPS Pharm Sci Tech, p: 8.

15. Higuchi T (1963) Mechanism of sustained action medication: Theoretical analysis of rate of release of solid drugs dispersed in solid matrices. J Pharm Sci 52: 1145-1149.

16. Hixson AW, Crowell JH (1931) Dependence of reaction velocity upon surface and agitation. Ind Eng Chem 23: 923-931.

17. Siepmann J, Peppas NA (2001) Modeling of drug release from delivery systems based on Hydroxypropylmethylcellulose (HPMC). Adv Drug Deliv Rev 48: 139-157.

18. Korsmeyer RW, Gurny R, Doelker E, Buri P, Peppas NA (1983) Mechanisms of solute release from porous hydrophilic polymers. Int J Pharm 15: 25-35.

19. Onyechi JO, Okafo SE (2016) Evaluation of carnauba wax in sustained release Diclofenac sodium tablet formulation. J Chem Pharm Res 8: 714-721.

20. Coughlan DC, Quilty FP, Corrigan OI (2004) Effect of drug physiochemical properties on swelling/deswelling kinetics and pulsatile drug release from thermoresponsive poly (Nisopropylacrylamide) hydrogels. J Cont Rel 98: 97114. 